\title{
Development of a Scale of Narcissism in Social Media and Investigation of Its Psychometric Characteristics
}

\author{
Seher Akdeniz ${ }^{1}$, Hatice Budak ${ }^{2}$ \& Zeynep G. Ahç1 ${ }^{1}$ \\ ${ }^{1}$ Psychology Department, Social and Humanity Science Faculty, KTO Karatay University, Turkey \\ ${ }^{2}$ Sociology Department, Social and Humanity Science Faculty, KTO Karatay University, Turkey \\ Correspondence: Seher Akdeniz, Psychology Department, KTO Karatay University, Alaaddin Kap street, Akabe, \\ No:130, Karatay, Turkey.
}

Received: August 18, 2021

Accepted: October 18, 2021

Online Published: January 26, 2022

doi:10.5539/ies.v15n1p200

URL: https://doi.org/10.5539/ies.v15n1p200

\begin{abstract}
Narcissism in social media reveals itself differently than in daily social interactions. Therefore, the present study aimed to develop a Scale of Narcissism in Social Media through the lens of the Narcissistic Admiration and Rivalry Model and to investigate its psychometric characteristics. The total sample of the study consisted of 740 participants between 18 and 65 years of age for exploratory and confirmatory factor analysis. The exploratory factor analysis resulted in a 16 item and two-factor structure. The structure of the scale was in accordance with the theoretical framework and therefore factors are named Narcissistic Admiration and Narcissistic Rivalry. The results of the confirmative analysis showed that the fit indices were acceptable. Correlations of the scale with other narcissism scales demonstrated concurrent validity and reliability analysis showed acceptable internal consistency. The results of the study show that the Scale of Narcissism in Social Media is a valid and reliable tool for measurement and data collection.
\end{abstract}

Keywords: scale of narcissism in social media, narcissistic admiration, narcissistic rivalry, validity, reliability, university students, young adults

\section{Introduction}

Nowadays 3.81 billion people actively use social media, a figure accounting for $49 \%$ of the world population. Compared with last year's statistics for the same period, the number of social media users has increased by 304 million (We Are Social \& Hootsuite, 2020). Easily accessible social media platforms have changed the communication styles of individuals, enterprises, and even communities. Meanwhile, motives that urge people to create content in social media have become important research subjects. It is suggested that content creation in social media platforms meet various psychosocial needs such as showing affection, displaying negative emotions, gaining recognition, entertainment, and cognitive needs (Leung, 2013). Research also reveals that user-generated content in social media satisfy various needs such as social interaction, inquiry for information, fill in time, relaxation, hearing from others, documentation, productivity, and reward expectations (Whiting \& Williams, 2013; Sheldon \& Bryant, 2016; Ko, Cho, \& Roberts, 2005). It is also suggested that social media provides a good platform both for self-presentation and social interaction realized through shared content (Buffardi \& Campbell, 2008). This fact has inspired researchers to investigate the correlations among social media addiction, motives to create content in social media platforms, personality and personality disorders (Ryan \& Xenos, 2011; Ooi et al., 2020).

Narcissism is an important personality trait with an idealized self-image at the core. Narcissist individuals generally believe that they are unique, special, and better than other people; they overpraise themselves (Buffardi \& Campbell, 2008). Narcissistic Personality Disorder, the pathological form of narcissism, is described in the DSM-V as a disorder characterized by a grandiose sense of self-importance, fantasies of unlimited success, belief in being special and unique, lack of empathy, feelings of envy, and arrogance (APA, 2013). However, in the non-clinical population, narcissism has been mainly investigated as a trait.

Campbell and Foster (2007) suggest that narcissism is a quality of self that has significant implications for thinking, feeling, and behaving. Narcissism exists in a continuum presenting no clear line between narcissistic and non-narcissistic people. For this reason, narcissism can be positively associated with leadership and 
subjective well-being, but it may also have negative outcomes such as aggressiveness and superficial relationships (McCain \& Campell, 2018).

Previous research suggests that non-pathological narcissism has at least two dimensions: grandiose and vulnerable narcissism (Miller \& Campell, 2008). The grandiose narcissism essentially involves a functional approach strategy. It reflects traits such as grandiose-self, aggressiveness, and dominance (Miller et al., 2011). It is a strong disposition guided by the motivation to seek targets of self-glorification and self-satisfaction. While, in the five-factor personality inventory, grandiose narcissism has a positive correlation with extraversion, it has a negative correlation with agreeableness and neuroticism (Paulhus \& Williams, 2002). Vulnerable narcissism, on the other hand, involves avoidance that tends towards emotional stress and which is also guided by the motive to define the threats for self-image and to combat these threats (Miller et al., 2011). Unsatisfied narcissistic needs give rise to shame, fury, and anxiety. A watchful stance focusing on perceived threats and the need for self-defense suppresses the reward-seeking behavior (Krizan, 2018). In the five-factor personality inventory, vulnerable narcissism positively correlated with neuroticism and negatively correlated with agreeableness and extroversion (Miller et al., 2010). The narcissism spectrum model (Krizan \& Herlache, 2018) provides a framework to integrate narcissism within the scope of personality and psychopathology. The feeling of an important self-image connects the dimensions of grandiosity and vulnerability. In short, the feeling of self-importance is common both dimensions.

The Narcissistic Admiration and Rivalry Model distinguish the two dimensions of grandiose narcissism, which are positively correlated with each other. There are two social strategies or universal urges underlying the motive of grandiosity in narcissism, namely self-enhancement, and self-protection. While narcissistic admiration reflects agentic traits, narcissistic rivalry involves antagonistic traits (Back et al., 2013). This differentiation aims at defining the self-regulatory process forming these two dimensions of grandiose narcissism, providing insight into its motivational foundations and explaining its social outcomes (Back, 2018). Narcissistic admiration is a strategy of self-enhancement that expresses the slogan "Get other people to admire you!". Besides ensuring higher self-respect and good feelings, it also feeds grandiose ego over and over again by making one feel special and admired. In encouraging ego to evoke admiration, exaggerated self-regulation mechanisms come into play through a self-enhancement strategy, consisting of three dimensions, namely an intense desire for uniqueness (emotional dimension), grandiose fantasies (cognitive dimension), and attractive, dominant, and extrovert behaviors (behavioral dimension). In a short time, this condition can evolve into desired outcomes such as social power (Back et al., 2013). Narcissistic rivalry, on the other hand, involves a narcissistic self-defence process characterized by hostility and fear of loss, which can be explained in the motto, "Never let others destroy you!". The individual makes great efforts characterized by strong self-regulative emotions to defend his/her grandiose self against any real or imagined aggressors. It not only involves passive inner reactions such as degrading others, but also social reactions of active character such as revenge. It is characterized by emotional (an intense desire for grandiosity), cognitive (degrading others), and behavioral (aggressiveness) dimensions. The probable social outcomes can be deterioration in relationships, being criticized, losing popularity and others' confidence. Here defence strategy is more dominant than self-enhancement. However, both narcissistic admiration and narcissistic rivalry are correlated with grandiose self (Back et al., 2013).

Several scales have been developed to identify the non-pathological narcissism in society. A pioneer scale that laid down the marker in this field was the Narcissistic Personality Inventory (NPI) which was developed by Raskin and Hall (1979) and later revised by Raskin and Terry (1988). NPI suggests that narcissism can be investigated under seven dimensions, being "authority, self-sufficiency, superiority, vanity, exhibitionism, entitlement, and exploitativeness". Ackerman et al. (2011), on the other hand, suggested that it could also be represented in three dimensions, namely 'eadership/authority, grandiose/exhibitionism, and entitlement/exploitativeness'. While the Narcissistic Grandiose Scale (Rosenthal et al., 2020), a measurement tool developed to distinguish narcissistic grandiosity from self-esteem, aims at measuring grandiose narcissism based on a single-factor structure, the Grandiose Narcissism Scale developed by Foster et al. (2015) is designed to measure narcissism based on the above-mentioned seven-factor model developed by Raskin and Terry (1988). Arguing that NPI was not suitable for new conceptualizations in narcissism, that no consensus has been achieved in the literature regarding its factor structure, and that many of the items focused only on the criteria of assertive and dominant behaviors as well as grandiosity, Back et al.(2013) developed Narcissistic Admiration and Rivalry Scale. The authors investigated grandiose narcissism based on self-regulation processes. The admiration dimension consists of three sub-dimensions, i.e. grandiosity, uniqueness, and charmingness. The rivalry dimension, on the other hand, consisted of devaluing others, aggression, and striving for supremacy.

Social media involves, by its very nature, the potential of coming into prominence in a follower group and 
receiving, in turn, feedback from this group. As a result, there is a growing interest in the public and academic community as to whether social media reflects narcissism or contributes to it (Barry \& McDougall, 2018). Narcissistic individuals' characteristics, such as their tendency to prefer less intimate relationships (Bergman et al., 2011), attention needs (Morf \& Rhodewalt, 2001), desire for higher status social connections (Campbell, 1999), and the suitable environment social media provides for these needs (McCain \& Campbell, 2018) have attracted researchers to conduct studies investigating the relations between social media use and narcissism.

Some studies on individual differences revealed that narcissism is positively correlated with various online social network activities (McCain \& Campbell, 2018; Carpenter, 2012). Narcissism was associated with status updates, a higher amount of interaction, and sharing photographs on Facebook profiles (Buffardi \& Campbell, 2008). However, it is grandiose narcissism, rather than vulnerable narcissism, that is actually related to social media use (Gnambs \& Appel, 2017). Grandiose narcissism predicts the number of selfies, especially those revealing more body parts and showing just the self (Barry et al., 2017). On the other hand, it is not easy to detect vulnerable narcissism on social media (Miller et al., 2011, McCain \& Campbell, 2018). Alternatingly, it is suggested that constant presence in social media and virtual positive relationships could increase narcissism (Gentile, Twenge, Freeman \& Campbell, 2012). This second viewpoint predicts that social media use may contribute to narcissism even in more humble individuals (Twenge \& Campbell, 2010).

Researchers have used various models to investigate narcissism on social media. One approach is to get observers to rate social media postings in terms of narcissism (Vazire et al., 2008; Buffardi \& Campbell, 2008). The downside of these studies is subjective observer decisions. Remarkably, the majority of the studies have focused on the general nature of social media activities such as status updates, number of followers, etc. (Barry \& McDougall, 2018). However, it is not realistic to link a more active presence in social media directly with narcissism. Meta-analysis studies have shown that narcissism does not strongly predict the frequency of status updates and the number of selfie postings (McCain \& Campbell, 2018). Researchers who conducted one of the first studies on generation $\mathrm{Y}$ report that non-pathological narcissism is not associated with the essential parameters like frequency and time in social media usage, but linked with intentions in sharing posts instead (e.g. to inform followers of activities, to create a positive image, etc.) (Bergman, Fearrington, Davenport, \& Bergman, 2011). It is also possible that self-presentation in social media has become a cultural norm, therefore it is not necessarily an indicator of problematic self-perception (Barry \& McDougall, 2018).

Research on social media and narcissism should therefore consider the important motives in social media use with a particular focus on narcissism. But no tool has been found in the literature to specifically measure narcissism in social media. To this end, research has generally used the Narcissistic Personality Inventory and other scales traditionally used in studies on social media (Andreassen, Pallesen, \& Griffiths, 2017). However, social media has become a culture with specific characteristics that require the consideration of individual differences concerning the intentions to use social media. Therefore, the unavailability of such a measurement tool represents an important gap for researchers performing field surveys. Accordingly, the purpose of the present study was to develop a measurement tool to fill this gap observed in the literature and investigate its psychometric properties. The narcissism on the social media scale will not only provide a reliable and valid tool for field surveys but also have a guiding effect for future research in this field.

\section{Method}

\subsection{Participants}

The data were collected from two different voluntary participant groups on the Google Forms platform. In the pilot study, the study group consisted of 105 adults between 18 and 40 years of age (Mean=23.49), of whom $60 \%$ were women and $40 \%$ were men. The second group was recruited for the exploratory and confirmatory factor analysis (CFA) which consisted of 740 university students and young adults. After the data set were randomly divided into two groups there were 340 participants for the exploratory factor analysis (EFA) of whom $64.4 \%$ were women and $35.6 \%$ were men between 18 and 65 years old (Mean=26,12). The CFA was conducted on 400 participants of whom $66 \%$ were women $34 \%$ were men, aged between 18 and 64 years (Mean=26.30).

\subsection{Measures}

\subsubsection{Narcissistic Personality Inventory}

The NPI is a tool that was developed by Ames et al. (2009) and adapted into Turkish by Atay (2009). The inventory has 7 subscales: authority, self-sufficiency, superiority, vanity, exhibitionism, entitlement, and exploitativeness. Higher scores indicate a higher level of narcissism. While Atay (2009) reported a .65 Cronbach's alpha coefficient for the scale, it was .73 in the present study. 


\subsubsection{Dirty Dozen}

It is a short measure of the Dark Triad developed by Jonason and Webster (2010). The scale was adapted into Turkish by Özsoy et al. (2017). The Cronbach's alpha coefficient of the scale was $.80, .81$, and .67 for narcissism, machiavellianism, and psychopathy, respectively. The Cronbach's alpha coefficient in the present study, on the other hand, was $.83, .81$, and .71 for narcissism, machiavellianism, and psychopathy, respectively.

\subsection{Analysis and Procedure}

Ethical approval was obtained from the Human Research Ethics Committee of KTO Karatay University (No:46409256-300). Narcissism on Social Media Scale (NSMS) was administered online to a total number of 761 participants in the study; however, 21 cases that were identified as extreme values and affected normality of the data were removed from the data set. After randomly splitting the data, EFA and parallel analysis were conducted on 340 participants. Confirmatory factor analyses were conducted on 400 participants. In EFA analysis, a minimum value of $30 \%$ for overall variance and $5 \%$ for each sub-dimension were considered acceptable, and overlapping items were excluded (Seçer, 2015). Besides each item was selected according to its factor loadings with a minimum value of .30 in both exploratory and confirmatory factor analysis and the lowest Cronbach's alpha coefficient value was .70 (Tabachnick \& Fidell, 2013).

In the data analysis, the SPSS 22 package program was used for the reliability, EFA, and concurrent validity; SPSS 22 syntax (O'Connor, 2000) for parallel analysis and LISREL 9.1 package program for the confirmatory factor analysis. In Confirmatory Factor Analysis, it was considered that $C F I$ and $G F I \geq .90$ were adequate and $\geq .95$ perfect fit. For $G F I, \geq .85$ was adequate and $\geq .90$ perfect, and for $R M R, R M S E A$, and SRMR $\leq .08$ was adequate $\leq .50$ perfect fit criteria (Schumacker \& Lomax, 2004).

\section{Results}

\subsection{Scale Development Process}

\subsubsection{Creating the Test Form}

The Narcissistic Admiration and Rivalry Model was created based on the model available in the related literature (Back et al., 2013), and an item pool consisting of 83 items was created based on narcissistic personality disorder criteria defined in DSM 5 and narcissistic admiration and rivalry concept defined in the literature. The items included several options to reflect the cognitive, behavioral, and emotional properties. The items were rated on a five-point Likert scale with options ranging from "Strongly Agree" to "Strongly Disagree".

The first form of the scale was examined by three specialists specialized in the fields of Psychiatry, Psychology, and Psychological Counselling, as a result of which six items were removed from the item pool in line with the specialists' proposals. Then, a Turkish language specialist evaluated each item and suggested corrections were made. In the third step, the pilot study was conducted and the scale's item fit and internal consistency were examined. Items with .30 and below item-scale correlations were removed from the form (Tabachnick \& Fidell, 2013). Besides items with too high inter-item correlations (.90 and above) were also removed. The Cronbach's alpha coefficient of the final form with 16 items was .82, which was considered to be acceptable (Büyüköztürk, 2012). The specialists who reviewed the internal consistency of the scale, overall item correlations, and the items with good fit reported no problems that would influence content validity. Thus, a 16-item form was administered to 761 participants. KMO value was .88 and Barlett value was $1455.02(\mathrm{p}<.001)$. EFA and parallel analysis were performed on 340 participants to determine the factor structure of the scale. Parallel analysis (O'Connor, 2000) for the 95th percentile in 100 random data sets suggested a two-component solution. At root 3, the actual eigenvalue (1.04) fell below the mean random data eigenvalue (1.23) and percentile (1.28). Principal Component Analysis was used for factor extraction. Then we rotated a two-factor solution via the Promax algorithm $(\kappa=4)$ to allow correlations among factors (Tabachnick \& Fidell, 2013). The resulting factors were labeled accordingly: narcissistic admiration and narcissistic rivalry. This solution accounted for $42.09 \%$ of the total variance. The results of the EFA and parallel analysis revealed that a two-factor structure would provide a good fit. These preliminary findings suggested that the data set was fit for analysis. Table 1 shows the results of EFA. 
Table 1. The factor structure of the scale $(\mathrm{N}=340)$

\begin{tabular}{|c|c|c|c|}
\hline Item & $\begin{array}{c}\text { Factor_1 } \\
\text { NA }\end{array}$ & $\begin{array}{c}\text { Factor_2 } \\
\text { NR }\end{array}$ & $\begin{array}{c}\text { Item-Total } \\
\mathrm{r}\end{array}$ \\
\hline s12-I prefer to be in touch with people on social websites who would help me achieve my goals & .774 & & .429 \\
\hline s16-I share contents that would increase my prestige in social websites & .766 & & .518 \\
\hline s11-I follow people who have high social status, occupation and education level on social websites. & .673 & & .386 \\
\hline s1-I share contents which exhibit my intelligence on social websites & .596 & & .423 \\
\hline s9-I wonder people's comments on me and my sharings on social websites. & .584 & & .480 \\
\hline s10-I deserve to be appreciated because of my sharings on social websites. & .561 & & .620 \\
\hline s15-I deserve my friends' and my followers' attention on social websites & .553 & & .693 \\
\hline $\begin{array}{l}\text { s6-I share my activities and photographs with my teachers/executives from my school/workplace on } \\
\text { social websites. }\end{array}$ & .481 & & .370 \\
\hline s3-I pay attention how I look on photos before I share them on social websites. & .430 & & .405 \\
\hline s5-I get angry when my followers pay attention to others more than me. & & .773 & .455 \\
\hline s4-I criticize people's shortcomings on social websites. & & .726 & .418 \\
\hline s14-I find secret videotapes of others on social websites amusing & & .690 & .367 \\
\hline s8-I think people who criticize my sharings on social websites are actually jealous of me. & & .666 & .544 \\
\hline $\begin{array}{l}\text { s2-I remove people from my followers list and block them when they criticize my sharings on social } \\
\text { websites }\end{array}$ & & .634 & .382 \\
\hline s7-I feel sadness when my sharings don't get likes as much as I expect. & & .527 & .543 \\
\hline s13-I think many people imitate my sharings and contents on social websites. & & .443 & .502 \\
\hline Explained Variance & $31.66 \%$ & $10.42 \%$ & $\begin{array}{c}\text { Total } \\
42.09 \%\end{array}$ \\
\hline
\end{tabular}

Note. $\mathrm{NA}=$ narcissistic admiration; $\mathrm{NR}=$ narcissistic rivalry.

According to Table 1; Factor 1 (NA) consists of 9 items, with factor loadings varying between .77 and .43. On the other hand, Factor_2 (NR) consists of 7 items, with factor loadings varying between .77 and .44 . EFA results revealed that the two-factor structure provided an optimal solution to the data.

Internal consistency and two split-half reliability analyses were performed to provide evidence of reliability for the confirmed structure of the scale. The results are shown in Table 2.

Table 2. Results of reliability analysis

\begin{tabular}{ccc}
\hline Variable & Cronbach's alpha & Two Split-half reliability \\
\hline NA & .80 & .79 \\
NR & .76 & .76 \\
Total & .84 & .73 \\
\hline
\end{tabular}

Note. $\mathrm{NA}=$ narcissistic admiration; $\mathrm{NR}=$ narcissistic rivalry.

The results in Table 2 reveals that internal consistency and two half-split reliability values were above the minimum proposed values which indicate adequate reliability of the scale (Robinson, Shaver, \& Wrightsman, 1991; Fraenkel, Wallen, \& Hyun, 2012).

To determine the model fit of the two-factor structure of the scale a CFA was performed. The maximum likelihood method was employed in the analysis.

Figure 1 shows the results of CFA $(\mathrm{N}=400)$. 


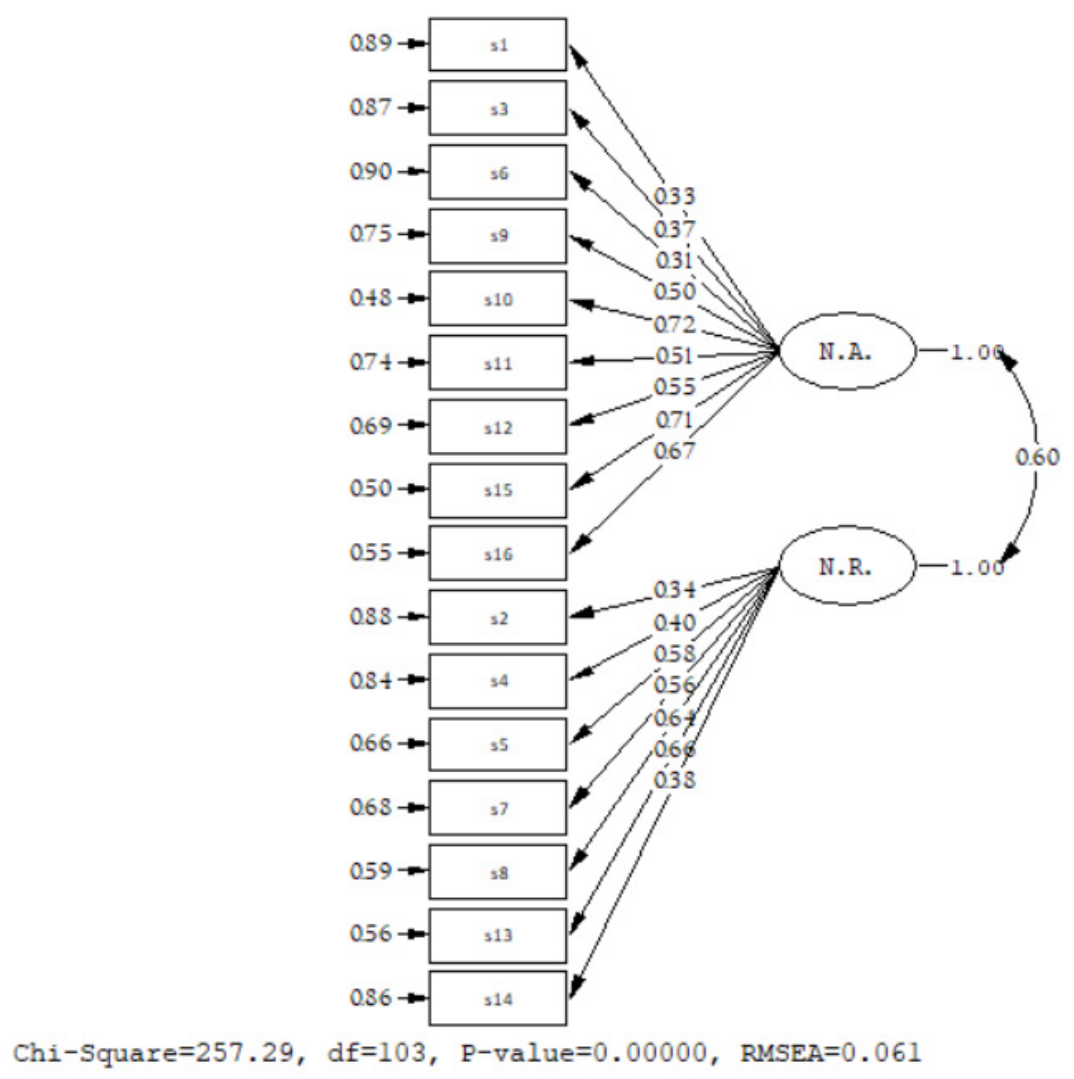

Figure 1. Standardized factor loadings of the items on two-factor structure (Note. N.A.=narcissistic admiration; N.R.=narcissistic rivalry)

Figure 1 shows that the 16 items' factor loadings in the CFA. They were all significant at $p<.05$. The standardised model of the two-factor structure provided a good fit, and the two-factor model was confirmed $\left(\chi^{2} / s d=2.49\right.$; RMSEA: .061, SRMR: .056, NFI: .90, CFI: .95, GFI: .93). In conclusion, it can be said that EFA and CFA results revealed that the scale has a valid structure.

To provide supporting evidence for the validity the SNSM was administered with NPI and the Dark Triad Scales and Pearson correlation coefficients were conducted to evaluate the relationship between the three scales. The results are given in Table 3.

Table 3. Results of correlation analysis $(\mathrm{N}=740)$

Note. ${ }^{*} p<.01$.

\begin{tabular}{lcccc}
\hline & NPI & Narcissism & Machiavellianism & Psychopathy \\
\hline Narcissistic Admiration & $.367^{* *}$ & $.489^{* *}$ & $.199^{* *}$ & .059 \\
Narcissistic Rivalry & $.393^{* *}$ & $.445^{* *}$ & $.453^{* *}$ & $.324^{* *}$ \\
Total Narcissism & $.438^{* *}$ & $.545^{* *}$ & $.357^{* *}$ & $.200^{* *}$ \\
\hline
\end{tabular}

Table 3 shows that NA had a positive and significant correlation with the NPI $(\mathrm{r}=.37, p<.01)$. The results further revealed that NA was also positively and significantly correlated with the Narcissism of the Short Dark Triad Scale $(\mathrm{r}=.49, p<.01)$ and also with Machiavellianism $(\mathrm{r}=.20, p<.01)$. The results indicated no correlation between NA and Psychopathy.

It was also found that NR was positively and significantly correlated with the NPI $(\mathrm{r}=.39, p<.01)$, narcissism 
sub-dimension of the Short Dark Triad Scale $(\mathrm{r}=.45, p<.01)$, and also with machiavellianism $(\mathrm{r}=.45, p<.01)$. The results indicate that the scale has concurrent validity.

\section{Discussion}

The scale developed in the study is based on the model in which grandiose narcissism, which enables the conceptualization of narcissism in a non-clinical population, is examined in two dimensions, namely narcissistic admiration and narcissistic rivalry. Even though these two dimensions are in correlation with each other and also with the overall narcissism score, it leads to different psychological results due to a differentiation in self-regulation mechanisms (Back et al., 2013).

The analysis results showed that the two-factor structure of the scale developed in the study indicated adequate fit values (Tabachnick \& Fidel, 2013). In conclusion, the findings from EFA and CFA yielded adequate construct validity for the scale.

The Cronbach's alpha and two split-half reliability tests also suggest adequate reliability (Tabachnick \& Fidel, 2013). The two split-half reliability values of the scale were also within the range of proposed values and adequate in terms of determining the reliability of the scale (Robinson, Shaver, \& Wrightsman, 1991; Fraenkel, Wallend, \& Hyun, 2012).

While NA of the SNSM had a moderate positive correlation with the narcissism of the Dark Triad, it had a weak positive correlation with Machiavellianism. The study found no significant correlation between NA and psychopathy. The NR had a positive moderate correlation with Narcissism, Machiavellianism, and psychopathy of the Dark Triad. Even though NA and NR of SNSM developed in the study are in correlation with each other, as is the case in the Narcissistic Admiration and Rivalry Model (Back et al., 2013), these findings confirm the suggestion that they have different manifestations arising from different self-regulation strategies. Leckelt et al. (2018) have provided evidence that NR has a stronger correlation with Machiavellianism and psychopathy. The manifestation of narcissistic admiration and rivalry in social media also revealed similar results.

The study suggests that SNSM has a positive and significant correlation with NPI. This result is in agreement with the findings observed by Back et al. (2013) suggesting that even though the Narcissistic Admiration and Rivalry Scale and NPI can capture the essential features of narcissism, they cannot be used interchangeably.

Although the present study provides significant findings that can contribute to the current literature on the phenomenon of narcissism in social media, it has certain limitations. One of these limitations concerns the development of the items. The scale items were developed based on face validity in line with DSM 5 and conceptual definitions of the narcissistic admiration and rivalry model. The lack of a second pilot study that asked participant opinions with an open-ended question can be considered another limitation. Besides, the study participants consisted of those who had tools and possibilities such as a PC, internet connection, etc., which can also be considered another limitation of the study (Gürbüz \& Şahin, 2017). However, since being a social media user was an inclusion criterion in the study, it can be regarded as an arguable limitation probably with a lower influence on study results.

To contribute to the current body of literature, it would be interesting to investigate narcissism in social media in terms of other social media outputs (e.g. social media addiction, altruistic behaviors, etc.). Another possible area of future research is the standardization of the narcissism scale for adolescents to study developmental trends.

\section{References}

Ackerman, R. A., Witt, E. A., Donnellan, M. B., Trzesniewski, K. H., Robins, R. W., \& Kashy, D. A. (2011). What does the narcissistic personality inventory really measure? Assessment, 18(1), 67-87. https://doi.org/10.1177/1073191110382845

Ames, D., Rose, P., \& Anderson, C. (2006). The NPI-16 as a short measure of narcissism. Journal of Research in Personality, 40(4), 440-450. https://doi.org/10.1016/j.jrp.2005.03.002

Andreassen, C. S., Pallesen, S., \& Griffiths, M. D. (2017). The relationship between addictive use of social media, narcissism, and self-esteem: Findings from a large national survey. Addictive behaviors, 64, 287-293. https://doi.org/10.1016/j.addbeh.2016.03.006

APA (2013). Diagnostic and statistical manual of mental disorders (5th ed.). Washington, DC: American Psychiatric Association.

Atay, S. (2009). Narsist Kişilik Envanterinin Türkçeye Standardizasyonu. Gazi Üniversitesi İktisadi ve İdari Bilimler Fakültesi Dergisi, 11(1), 181-196. 
Back, M. D. (2018). The narcissistic admiration and rivalry concept. In A. D. Hermann, A. B. Brunell, \& J. D. Foster (Eds.), The handbook of trait narcissism: Key advances, research methods, and controversies (pp. 57-67). New York, NY: Springer. https://doi.org/10.1007/978-3-319-92171-6_6

Back, M. D., Küfner, A. C., Dufner, M., Gerlach, T. M., Rauthmann, J. F., \& Denissen, J. J. (2013). Narcissistic admiration and rivalry: Disentangling the bright and dark sides of narcissism. Journal of Personality and Social Psychology, 105(6), 2013. https://doi.org/10.1037/a0034431

Barry, C. T., \& McDougall, K. H. (2018). Social media: Platform or catalyst for narcissism? In A. D. Hermann, A. B. Brunell, \& J. D. Foster (Eds.), The handbook of trait narcissism: Key advances, research methods, and controversies. New York, NY: Springer. https://doi.org/10.1007/978-3-319-92171-6_47

Barry, C. T., Doucette, H., Loflin, D. C., Rivera-hudson, N., \& Herrington, L. L. (2017). "Let me take a selfie": Associations between self-photography, narcissism, and self-esteem. Psychology of Popular Media Culture, 6(1), 48-60. https://doi.org/10.1037/ppm0000089

Bergman, S. M., Fearrington, M. E., Davenport, S. W., \& Bergman, J. Z. (2011). Millennials, narcissism, and social networking: What narcissists do on social networking sites and why. Personality and Individual Differences, 50(5), 706-711. https://doi.org/10.1016/j.paid.2010.12.022

Buffardi, L. E., \& Campbell, W. K. (2008). Narcissism and social networking web sites. Personality and social psychology bulletin, 34(10), 1303-1314. https://doi.org/10.1177/0146167208320061

Büyüköztürk, Ş. (2012). Sosyal bilimler için veri analizi el kitabl: İstatistik, araştırma deseni, SPSS uygulamalarl ve yorum [Data analysis handbook for social sciences: Statistics, research design, SPSS applications and interpretation]. Ankara: Pegem Akademi.

Campbell, W. K. (1999). Narcissism and romantic attraction. Journal of Personality and Social Psychology, 77(6), 1254-1270. https://doi.org/10.1037/0022-3514.77.6.1254

Campbell, W. K., \& Foster, J. D. (2007). The narcissistic self: Background, an extended agency model, and ongoing controversies. In C. Sedikides, \& S. J. Spencer (Eds.), The self (pp. 115-138). New York, NY: Psychology Press.

Carpenter, C. J. (2012). Narcissism on Facebook: Self-promotional and anti-social behavior. Personality and Individual Differences, 52(4), 482-486. https://doi.org/10.1016/j.paid.2011.11.011

Foster, J. D., McCain, J. L., Hibberts, M. F., Brunell, A. B., \& Johnson, R. B. (2015). The Grandiose Narcissism Scale: A global and facet-level measure of grandiose narcissism. Personality and individual differences, 73, 12-16. https://doi.org/10.1016/j.paid.2014.08.042

Fraenkel, J. R., Wallen, N. E., \& Hyun, H. H. (2012). How to Design and Evaluate Research in Education (Edisi Kedelapan ed.). (S. Kiefer, Penyunt.) New York: McGrawHill.

Gentile, B., Twenge, J. M., Freeman, E. C., \& Campbell, W. K. (2012). The effect of social networking websites on positive self-views: An experimental investigation. Computers in Human Behavior, 28(5), 1929-1933. https://doi.org/10.1016/j.chb.2012.05.012

Gnambs, T., \& Appel, M. (2017). Narcissism and social networking behavior: A meta-analysis. Journal of Personality, 86(2), 200-212. https://doi.org/10.1111/jopy.12305

Gürbüz, S., \& Şahin, F. (2017). Sosyal bilimlerde araştırma yöntemleri: Felsefe-yöntem-analiz (4. Bask1), Ankara: Seçkin.

Jonason, P. K., \& Webster, G. D. (2010). The dirty dozen: A concise measure of the dark triad. Psychological Assessment, 22(2), 420-432. https://doi.org/10.1037/a0019265

Ko, H., Cho, C.H., \& Roberts, M. S. (2005). Internet uses and gratifications: A structural equation model of $\begin{array}{lllll}\text { interactive advertising. Journal of } & \text { Advertising, }\end{array}$ https://doi.org/10.1080/00913367.2005.10639191

Krizan, Z. (2018). The narcissism spectrum model: A spectrum perspective on narcissistic personality. In A. D. Hermann, A. B. Brunnel, \& J. D. Foster (Eds.), Handbook of trait narcissism. Key advances, research methods, and controversies (pp. 15-25). Cham: Springer. https://doi.org/10.1007/978-3-319-92171-6_2

Krizan, Z., \& Herlache, A. D. (2018). The narcissism spectrum model: A synthetic view of narcissistic personality. Personality and Social Psychology Review, 22(1), 3-31. https://doi.org/10.1177/1088868316685018 
Leckelt, M., Wetzel, E., Gerlach, T. M., Ackerman, R. A., Miller, J. D., Chopik, W. J., ... Back, M. D. (2018). Validation of the Narcissistic Admiration and Rivalry Questionnaire Short Scale (NARQ-S) in convenience and representative samples. Psychological Assessment, 30(1), 86-96. https://doi.org/10.1037/pas0000433

Leung, L. (2013). Generational differences in content generation in social media: The roles of the gratifications sought and of narcissism. Computers in Human Behavior, 29(3), 997-1006. https://doi.org/10.1016/j.chb.2012.12.028

McCain, J. L., \& Campbell, W. K. (2018). Narcissism and social media use: A meta-analytic review. Psychology of Popular Media Culture, 7(3), 308-327. https://doi.org/10.1037/ppm0000137

Miller, J. D., \& Campbell, W. K. (2008). Comparing clinical and social-personality conceptualizations of narcissism. Journal of Personality, 76(3), 449-476. https://doi.org/10.1111/j.1467-6494.2008.00492.x

Miller, J. D., Dir, A., Gentile, B., Wilson, L., Pryor, L. R., \& Campbell, W. K. (2010). Searching for a vulnerable dark triad: Comparing factor 2 psychopathy, vulnerable narcissism, and borderline personality disorder. Journal of Personality, 78(5), 1529-1564. https://doi.org/10.1111/j.1467-6494.2010.00660.x

Miller, J. D., Hoffman, B. J., Gaughan, E. T., Gentile, B., Maples, J., \& Keith Campbell, W. (2011). Grandiose and vulnerable narcissism: A nomological network analysis. Journal of Personality, 79(5), 1013-1042. https://doi.org/10.1111/j.1467-6494.2010.00711.x

Morf, C. C., \& Rhodewalt, F. (2001). Unraveling the paradoxes of narcissism: A dynamic self-regulatory processing model. Psychological Inquiry, 12(4), 177-196. https://doi.org/10.1207/S15327965PLI1204_1

O'Connor, B. P. (2000). SPSS and SAS programs for determining the number of components using parallel analysis and Velicer's MAP test. Behavior Research Methods, Instrumentation, and Computers, 32, 396-402. https://doi.org/10.3758/BF03200807

Ooi, J., Michael, J., Lemola, S., Butterfill, S., Siew, C. S., \& Walasek, L. (2020). Interpersonal Functioning in Borderline Personality Disorder Traits: A Social Media Perspective. Scientific Reports, 10(1), 1-8. https://doi.org/10.1038/s41598-020-58001-x

Özsoy, E., Rauthmann, J. F., Jonason, P. K., ve Ardıç, K. (2017). Reliability and validity of Turkish version of Dark Triad Dirty Dozen (DTDD-T), Short Dark Triad (SD3-T) and Single Item Narcissism Scale (SINS-T). Personality and Individual Differences, 117, 11-14. https://doi.org/10.1016/j.paid.2017.05.019

Paulhus, D. L., \& Williams, K. M. (2002). The dark triad of personality: Narcissism, Machiavellianism and psychopathy. Journal of Research in Personality, 36(6), 556-563. https://doi.org/10.1016/S0092-6566(02)00505-6

Raskin, R. N., \& Hall, C. S. (1979). A narcissistic personality inventory. Psychological Reports, 45(2), 590. https://doi.org/10.2466/pr0.1979.45.2.590

Raskin, R., \& Terry, H. (1988). A principal-components analysis of the Narcissistic Personality Inventory and further evidence of its construct validity. Journal of Personality and Social Psychology, 54(5), 890-902. https://doi.org/10.1037/0022-3514.54.5.890

Robinson, J. P., Shaver, P. R., \& Wrightsman, L. S. (1991). Criteria for scale selection and evaluation. In J. P. Robinson, P. R. Shaver, \& L. S. Wrightsman (Eds.), Measures of personality and social psychological attitudes (pp. 1-16). New York: Academic. https://doi.org/10.1016/B978-0-12-590241-0.50005-8

Rosenthal, S. A., Hooley, J. M., Montoya, R. M., van der Linden, S. L., \& Steshenko, Y. (2020). The narcissistic grandiosity scale: A measure to distinguish narcissistic grandiosity from high self-esteem. Assessment, 27(3), 487-507. https://doi.org/10.1177/1073191119858410

Ryan, T., \& Xenos, S. (2011). Who uses Facebook? An investigation into the relationship between the Big Five, shyness, narcissism, loneliness, and Facebook usage. Computers in human behavior, 27(5), 1658-1664. https://doi.org/10.1016/j.chb.2011.02.004

Schumacker, R. E., \& Lomax, R. G. (2004). A beginner's guide to structural equation modeling (2nd ed.). Mahwah, NJ: Erlbaum. https://doi.org/10.4324/9781410610904

Seçer, İ. (2015). SPSS ve LISREL ile pratik veri analizi [Practical data analysis with SPSS and LISREL] Ankara: Anı.

Sheldon, P., \& Bryant, K. (2016). Instagram: Motives for its use and relationship to narcissism and contextual age. Computers in human Behavior, 58, 89-97. https://doi.org/10.1016/j.chb.2015.12.059 
Tabachnick, B., \& Fidell, L. (2013). Using multivariate statistics (6th ed.). Boston: Pearson.

Twenge, J. M., \& Campbell, W. K. (2010). The narcissism epidemic: Living in the age of entitlement. New York: Free Press.

Vazire, S., Naumann, L. P., Rentfrow, P. J., \& Gosling, S. D. (2008). Portrait of a narcissist: Manifestations of narcissism in physical appearance. Journal of Research in Personality, 42(6), 1439-1447. https://doi.org/10.1016/j.jrp.2008.06.007

We Are Social \& Hootsuite. (2020). Digital 2020 Global Digital Overview. Retrieved from https://wearesocial.com/digital-2020

Whiting, A., \& Williams, D. (2013). Why people use social media: a uses and gratifications approach. Qualitative Market Research: An International Journal, 16(4), 362-369. https://doi.org/10.1108/QMR-06-2013-0041

\section{Copyrights}

Copyright for this article is retained by the author(s), with first publication rights granted to the journal.

This is an open-access article distributed under the terms and conditions of the Creative Commons Attribution license (http://creativecommons.org/licenses/by/4.0/). 